\title{
Modelling Short Crack Propagation under Variable Structural and Thermal Loadings
}

\author{
Alexander Bosch ${ }^{1}$ and Michael Vormwald ${ }^{2}$ \\ ${ }^{1}$ MTU Aero Engines AG \\ ${ }^{2}$ Technische Universität Darmstadt
}

November 9, 2020

\begin{abstract}
Concepts for crack propagation as well as fatigue assessment under variable mechanical and thermal loadings are unestablished. For variable mechanical loadings, the damage parameter $\mathrm{P}_{\mathrm{J}}$ is well known, for thermal loadings the damage parameter $\mathrm{D}_{\mathrm{TMF}}$ is established. Both parameters base on the effective cyclic J-Integral, still the definition is different. The damage parameters $\mathrm{P}_{\mathrm{J}}$ considers the effective stress and strain ranges from the upper reversal point of each load cycle to the point of crack closure. Depending on the loading sequence the point of crack closure is treated as a history variable. In addition, with a crack length dependant fatigue limit, the most important sequence effects are considered. A new $\mathrm{P}_{\mathrm{J}}$-based concept is developed by considering additional sequence effects. In comparison to experimental results, the developed concept is able to reduce scattering in the range of constant amplitude loading tests.
\end{abstract}

\section{Hosted file}

Paper-FFEMS-Bosch-2020-11-07.pdf available at https://authorea.com/users/374101/articles/ 491725-modelling-short-crack-propagation-under-variable-structural-and-thermal-loadings 